\title{
In vitro Evaluation of Color Changes of Aesthetic Orthodontic Elastic Ligatures
}

\author{
Evaluación in vitro de los Cambios de Color \\ en Ligaduras Elásticas Ortodónticas Estéticas
}

\begin{abstract}
Ludimila Kasberger Silva*; Bruna Coser Guignone*; Klinger de Castro Marinho*; Marcelo Coelho Goiato*;

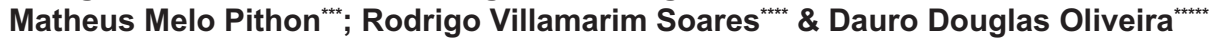

SILVA, L. K.; GUIGNONE, B. C.; MARINHO, K. C.; GOIATO, M. C.; PITHON, M. M.; SOARES, R. V. \& OLIVEIRA, D. D. In vitro evaluation of color changes of aesthetic orthodontic elastic ligatures. Int. J. Odontostomat., 8(3):399-403, 2014.

ABSTRACT: The objective of this study was to evaluate the possible changes in color of aesthetic elastic ligatures soaked in different solutions. Five different brands of aesthetic elastic ligatures were evaluated in the present study. Measurement of the discs' color was performed using a reflectance spectrophotometer (UV-visible spectrophotometer, UV2450, Shimadzu®, Kyoto, Japan). Subsequently, the discs were immersed in artificial saliva (AS) or three different solutions: red wine (RW) (Miolo Terranova ${ }^{\circledR} 2010$, Casa Nova, Brazil), coffee (CF) (Café Três Corações ${ }^{\circ}$, RioGrande do Norte, Brazil) or Coca-Cola ${ }^{\circledR}(\mathrm{CC})$ (Coca-Cola ${ }^{\circledR}$, Belo Horizonte, Brazil). It was determined that the tested solutions were able to cause color changes in the aesthetic elastic ligatures. The coffee solution caused the greatest color change in all of the brands of ligatures evaluated, followed by the red wine solution. In conclusion, OSE and GAC brands of aesthetic elastic ligatures displayed the best performance.

KEY WORDS: orthodontic ligatures, elastic ligatures, color changes, aesthetic orthodontic appliances.

\section{INTRODUCTION}

There has been a growing demand for aesthetic orthodontic appliances in clinics, especially among adults. To meet this demand, ceramic brackets, which have the great advantage of being transparent, have been developed (Ryu et al., 2011; Nishio et al., 2004; Samruajbenjakul \& Kukiattrakoon, 2009). Although the aesthetic advantages are greatly enhanced by these materials, the improvement is not complete because aesthetic brackets and ligatures of these appliances still face the challenge of maintaining their color stability in the oral environment. This issue is included in the majority of patient's questions and inquiries regarding the use of these types of devices and represents one of the major challenges for the orthodontic materials industry.

Orthodontic elastic ligatures are composed of polyurethane and can be produced by matrix molding or modular injection processes (Ardeshna \& Vaidyanathan, 2009; Renick et al., 2004). Polyurethanes are not inert materials, and they decompose when in prolonged contact with enzymes, water or humid heat (Han et al., 2011; Mohamed et al., 2011). There are reports that these ligatures may discolor or stain if the patient eats certain types of foods or uses mouthwash or lipstick (Ardeshna et al.; Kim \& Lee, 2009). This effect can cause problems because, whereas the ceramic brackets are somewhat resistant to staining, the aesthetic elastic ligatures do stain.

A number of studies have been conducted on elastic ligatures, investigating their loss of force (Lacerda Dos Santos et al., 2011), the frictional resistance of the elastic chains (Baccetti \& Franchi, 2006; Chimenti et al., 2005), the prevention of caries due to the release of fluoride by the ligatures (Benson

\footnotetext{
Private Practice and Former Orthodontic Residents, Pontifical Catholic University of Minas Gerais, Belo Horizonte, Brazil.

* Associate professor, School of Dentistry, Universidade Estadual Júlio de Mesquita Filho, Araçatuba, Brazil.

*** Professor of Orthodontics, Southwest Bahia State University (UESB), Jequié, Brazil.

**** Program Director of Periodontics, Pontifical Catholic University of Minas Gerais, Belo Horizonte, Brazil.

*tom* Program Director of Orthodontics, Pontifical Catholic University of Minas Gerais, Belo Horizonte, Brazil.
} 
et al., 2004a, 2004b) and their overall flexibility (Renick et al.), elasticity (Huget et al., 1990; von Fraunhofer et al., 19929) and degradation (Lacerda Dos Santos et al.; dos Santos et al.; Santos et al., 2011). However, although the limitations derived from the discoloration of elastic ligatures are well known, there are few quantitative studies on this subject (Ardeshna et al.; Kim \& Lee). Based on this premise, the aim of the present study was to evaluate the possible changes in color of aesthetic elastic ligatures soaked in different solutions.

\section{MATERIAL AND METHOD}

Five different brands of aesthetic elastic ligatures were evaluated in the present study (Table I). Given that the evaluation of a possible color change derived from ligatures' immersion in potentially staining solutions is performed using a spectrophotometer, and that these measurements

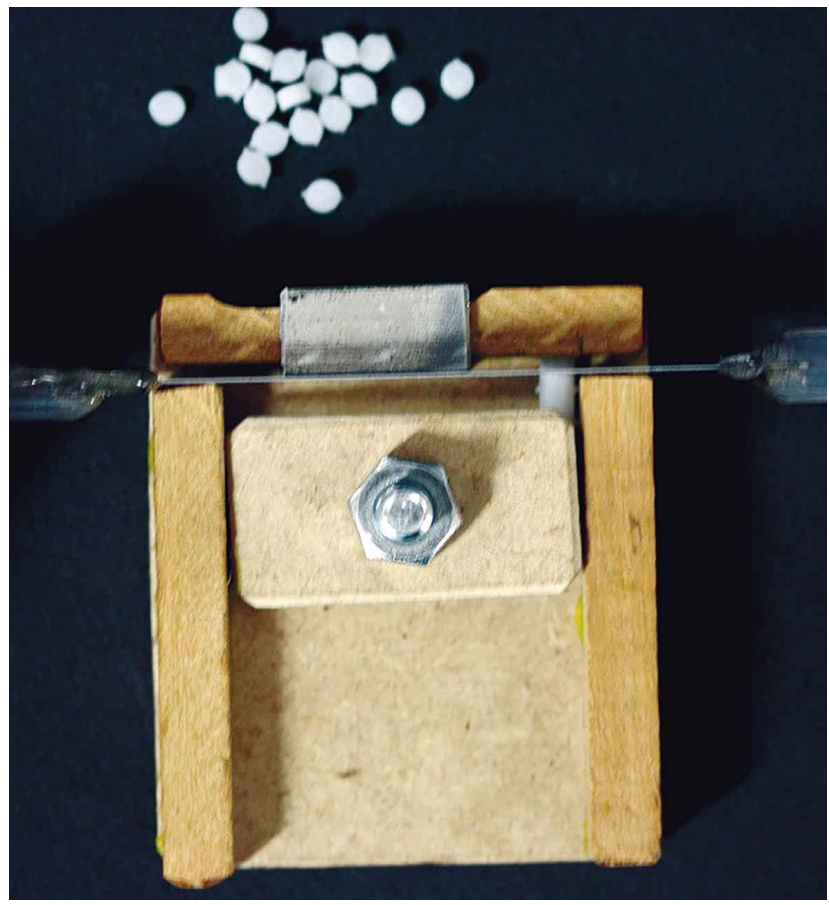

Fig. 1. Device used to standardize the elastic discs evaluated. should be performed on a flat surface, the arms of the module that holds the ligatures were used as representative samples. It is important to mention that the composition of the arms is identical to that of the ligatures. To standardize the samples, a cutting apparatus specifically designed for this experiment was used to generate flat discs (Fig. 1).

The measurement of the discs' color before being immersed in the solutions (i.e., dried discs) was performed using a reflectance spectrophotometer (UV-visible spectrophotometer, UV-2450, Shimadzu®, Kyoto, Japan). Subsequently, the discs were immersed in artificial saliva (AS) or three different solutions: red wine (RW) (Miolo Terranova ${ }^{\circledR}$ 2010, Casa Nova, Brazil), coffee (CF) (Café Três Corações $\AA$, RioGrande do Norte, Brazil) or CocaCola ${ }^{\circledR}$ (CC) (Coca-Cola $®$, Belo Horizonte, Brazil). These solutions were distributed into 4 small containers, each holding 8 ligature discs from the same manufacturer. Containers were stored in the dark at room temperature and solutions were changed every 24 hours. The group of ligatures immersed in AS was used to test the possible effects of hydration on discs' color.

The color change $\left(\Delta \mathrm{E}^{*} \mathrm{ab}\right)$ was calculated using the following equation18: $\mathrm{DE}^{*} \mathrm{ab}=\left[\left(\mathrm{DL}^{*}\right) \sum+\left(\mathrm{Da}^{*}\right) \sum\right.$ $\left.+\left(\mathrm{Db}^{*}\right) \Sigma\right] 1 / 2$

The changes in the color parameters ( $\mathrm{DL}^{*}, \mathrm{Da}^{*}$ and $\mathrm{Db}^{*}$ ) were calculated by subtracting the final values from the initial values (dry discs). Prior to each measurement, the discs were washed with distilled water to avoid the possibility of reading solution residues deposited on the surfaces of the discs.

The statistical significance $(p=0.05)$ of the effect of the different solutions on different brands of elastic ligatures was tested by one-way or two-way repeated measures analysis of variance (ANOVA, post hoc analysis - Fisher PLSD test). The statistical analysis was performed using the software SPSS 15.0 (SAS Institute Inc., Abacus Concepts, Cary, North Carolina, USA).

Table I. Orthodontic elastic ligatures tested.

\begin{tabular}{lcc}
\hline Manufacturer & Code & $\mathbf{n}$ \\
\hline Dynaflex, St. Ann, Missouri, USA & DF & 32 \\
GAC International Inc., Bohemia, New York, USA & GAC & 32 \\
G\&H Wire Company, Franklin, Indiana, USA & GH & 32 \\
Orthodontic Supply \& Equipment Co. Inc., Gaithersburg, Maryland, & OSE & 32 \\
3M/Unitek, Monrovia, California, USA & $3 \mathrm{M}$ & 32 \\
\hline
\end{tabular}




\section{RESULTS}

In the present study, we investigated the possible effects of four different solutions on the color of five orthodontic elastic ligature tie (OLT) brands. Analysis by two-way repeated measures ANOVA revealed main effects among the OLT brands $(p<0.001)$ and solutions $(p<0.001)$. Moreover, interactions between the OLT brands and the solutions $(p<0.001)$ were also observed. Therefore, to detect staining differences among solutions as well as OLT brand behavior in each solution, analysis by one-way repeated measures ANOVA was conducted.

It was observed that, independent of the OLT brand, the CF promoted a significantly higher DE in comparison with CC $(p<0.001), \operatorname{RW}(p=0.015)$ and AS $(p<0.001)$ (Table II). RW also promoted a significantly higher DE in comparison to CC $(p<0.001)$ and AS $(p<0.001)$, and DE differences between CC and AS were not encountered $(p=0.09)$.

The DE values among OLT brands after OLT exposure to specific solutions are described in Table III. The OLT brands evaluated in the present study did not exhibit significant differences in the DE values after 14 days of exposure to AS or to CC. In contrast, specific differences in the DE values among the OLT brands were observed after exposure to CF. The DE values of
DF, GH and 3M were not significantly different, although they were significantly $(p<0.0001)$ higher than those of GAC and OSE. GAC DE value was significantly $(p<0.0016)$ higher than that of OSE. Specific differences in the DE values among the OLT brands were also observed after exposure to RW. The DF, GAC, GH and $3 \mathrm{M} D E$ values were not significantly different, although the DF, GH and $3 \mathrm{M} D E$ values were significantly higher than that of OSE $(p=0.0011, p=0.0040$ and $p=0.0154$, respectively). Finally, the GAC and OSE DE values did not show significant differences $(p=0.1012)$.

\section{DISCUSSION}

It is essential that an orthodontist have an understanding of new materials to best utilize their qualities in the clinic while also being aware of their limitations (Kwon et al., 2002; Pithon et al., 2010; Eliades et al., 2005). Thus, an orthodontist who treats an adult patient seeking aesthetics throughout the orthodontic treatment, despite of being conscious of the good aesthetic stability offered by porcelain brackets, should also be aware and inform the patient of the possible color changes that may occur in aesthetic elastic ligatures.

Table II. Comparison of color changes (DE) promoted by different solutions.

\begin{tabular}{lcc}
\hline Solutions & $\Delta \mathbf{E}$ values & Significant $\mathbf{p}$ values $(\mathbf{p}<\mathbf{0 . 0 5})$ \\
\hline AS & 0.382 & \\
CF & 2.607 & CFxAS; CFxCC; CFxRW; RWxAS; RWxCC \\
CC & 0.728 & \\
RW & 2.092 & \\
\hline \multicolumn{4}{l}{ Artificial saliva (AS); red wine $(R W) ;$ coffee $(C F) ;$ Coca-Cola ${ }^{\circledR}(C C)$}
\end{tabular}

Table III. Orthodontic elastic ligatures (OLT) color changes after exposure to specific solutions.

\begin{tabular}{|c|c|c|c|c|c|c|}
\hline \multirow{2}{*}{ Solutions } & \multicolumn{5}{|c|}{$\Delta E$ values of OLT brands } & \multirow[t]{2}{*}{ Significant $p$ values $(p<0.05)$} \\
\hline & DF & GAC & GH & OSE & $3 \mathbf{M} \circledast$ & \\
\hline AS & $\begin{array}{c}0.443 \\
(0.243)\end{array}$ & $\begin{array}{c}0.408 \\
(0.298)\end{array}$ & $\begin{array}{l}0.438 \\
(0.167)\end{array}$ & $\begin{array}{c}0.311 \\
(0.198)\end{array}$ & $\begin{array}{c}0.374 \\
(0.213)\end{array}$ & None \\
\hline CF & $\begin{array}{l}2.269 \\
(0.301)\end{array}$ & $\begin{array}{c}1.841 \\
(0.235)\end{array}$ & $\begin{array}{l}2.115 \\
(0.301)\end{array}$ & $\begin{array}{c}1.384 \\
(0.120)\end{array}$ & $\begin{array}{l}2.277 \\
(0.220)\end{array}$ & $\begin{array}{l}\text { DFxGAC; DFxOSE; GACxGH; GACxOSE; } \\
\text { GACx3 M®; GHxOSE; OSEx3 M® }\end{array}$ \\
\hline $\mathrm{CC}$ & $\begin{array}{c}0.754 \\
(0.134)\end{array}$ & $\begin{array}{c}0.679 \\
(0.113)\end{array}$ & $\begin{array}{l}0.697 \\
(0.095)\end{array}$ & $\begin{array}{l}0.590 \\
(0.171)\end{array}$ & $\begin{array}{c}0.544 \\
(0.090)\end{array}$ & None \\
\hline RW & $\begin{array}{l}1.828 \\
(0.251)\end{array}$ & $\begin{array}{c}1.472 \\
(0.240)\end{array}$ & $\begin{array}{l}1.738 \\
(0.225)\end{array}$ & $\begin{array}{l}1.147 \\
(0.224)\end{array}$ & $\begin{array}{c}1.636 \\
(0.272)\end{array}$ & $\begin{array}{l}\text { DFxOSE; GHxOSE; } \\
\text { OSEx GAC® }\end{array}$ \\
\hline
\end{tabular}

DE values correspond to mean and standard deviation. Manufactures and solutions code are described on Table I and Table II, respectively. 
In the oral environment, the clinical behavior of the ligatures is problematic. When stretched beyond their elastic limit and maintained under constant tension, polyurethanes exhibit an undesired characteristic known as load relaxation (Huget et al.). The degradation of the polyurethane elastic ligatures in the oral environment may be associated with the process of color change undergone by the ligatures, and this process may be reduced by determining its cause (Kim \& Lee). In this context, the concentration and frequency of consumption of certain products in the diet can alter the staining caused by these products. In addition, considering that elastic ligatures manufactured by different manufacturers differ, variations in staining have been described in the literature (Renick et al.). Ardeshna \& Vaidyanathan evaluated the color change of different colors of elastic ligatures. These authors found that white and transparent ligatures had the highest DE values, suggested that the deposition of pigments from the solutions studied likely occurred on the surface of the ligatures and hypothesized that changes in the surface texture and morphology might contribute to the observed differences found among ligatures from different manufacturers.

In the present study, a reflectance spectrophotometer was used to evaluate the possible color changes due to orthodontic elastomeric ligatures staining. This instrument measures the amount of light at each wavelength reflected by a sample that is illuminated with polychromatic and diffuse light. Therefore, the basic operation of the device consists of illuminating the sample with white light and calculating the amount of reflected light at different wavelength intervals. From these data, a reflectance factor is recorded, and tristimulus values $\left(L^{*}, a^{*}\right.$ and $\left.b^{*}\right)$ calculated (Kwon et al.), where $L^{*}$ is a measure of brightness of the object, $a^{*}$ is a measure of the amount of red $\left(+a^{*}\right)$ and green $\left(-a^{*}\right)$ and $b^{*}$ the amount of yellow $\left(+b^{*}\right)$ and blue $\left(-b^{*}\right)$.

This analysis determined that CF caused the greatest color change in the ligatures, followed by RW, $\mathrm{CC}$ and AS (Table II). A large color change caused by coffee was also observed in a previous study. Using distilled water, $75 \%$ ethanol and $2 \%$ methylene blue solutions, Kim \& Lee showed that even distilled water is able to cause a color change in aesthetic elastic ligatures, although the values resulting from this solution were much lower than those resulting from the ethanol and $2 \%$ methylene blue. In the present study, different ligature brands showed no significant differences when exposed to AS or CC. However, exposure to CF caused greater color changes in DF, GH and $3 \mathrm{M}$, lower color changes in GAC and even fewer in OSE. When exposed to RW, DF, GH, and $3 \mathrm{M}$ again showed higher readings than those of GAC and OSE.

The present study showed that all solutions caused some color change in the aesthetic elastic ligatures evaluated, although more significant changes were observed in the samples exposed to CF and RW. Additionally, samples from specific manufacturers exhibited variations in performance, of which GAC and OSE exhibited the lowest changes and consequently, the greatest color stability in the solutions tested.

In everyday clinical orthodontics, upon placing the aesthetic devices, it is necessary to tell the patient about the color changes that aesthetic elastic ligatures experience over time due to exposure to the intraoral environment. The orthodontist's should select materials that are more resistant to color changes. It is also important to warn the patient about the staining potential of certain foods. Therefore, patients who drink coffee and/or red wine should be warned about the staining that can be caused by these solutions. Additionally, if the patient frequently drinks these beverages, the results of the present study indicate that the use of specific brands of ligatures (i.e., OSE and GAC) may be more appropriate.

\section{CONCLUSIONS}

i) Tested solutions were able to cause color changes in the aesthetic elastic ligatures; ii) The coffee solution caused the greatest color change in all of the brands of ligatures evaluated, followed by the red wine solution and iii) OSE and GAC brands of aesthetic elastic ligatures displayed the best performance.

SILVA, L. K.; GUIGNONE, B. C.; MARINHO, K. C.; GOIATO, M. C.; PITHON, M. M.; SOARES, R. V. \& OLIVEIRA, D. D. Evaluación in vitro de los cambios de color en ligaduras elásticas ortodónticas estéticas. Int. J. Odontostomat., 8(3):399-403, 2014.

RESUMEN: El objetivo de este estudio fue evaluar los posibles cambios en el color de ligaduras elásticas estéticas embebidas en diferentes soluciones. Cinco diferentes marcas de ligaduras elásticas estéticas fueron evaluados en el presente estudio. La medición de discos de color se realizó con un espectrofotómetro de reflectancia (espectrofotómetro UV-visible, UV-2450, Shimadzu®, Kyoto, Japón). A continuación, los discos se sumergieron en saliva artificial o tres soluciones diferentes: vino 
tinto (Miolo Terranova ${ }^{\circledR}$ 2010, Casa Nova, Brasil), café (Café Três Corações $₫$, RioGrande do Norte, Brasil) o Coca-Cola $₫$ (CocaCola $\AA$, Belo Horizonte, Brasil). Se determinó que las soluciones testeadas fueron capaces de causar cambios de color en las ligaduras elásticas estéticas. La solución de café causó el mayor cambio de color en todas las marcas de ligaduras evaluados, seguido por la solución de vino tinto. En conclusión, las marcas de ligaduras elásticas estéticas OSE y GAC muestran el mejor desempeño.

PALABRAS CLAVE: ligaduras ortodóncicas, ligaduras elásticas, cambios de color, aparatos de ortodoncia estéticos.

\section{REFERENCES}

Ardeshna, A. P. \& Vaidyanathan, T. K. Colour changes of orthodontic elastomeric module materials exposed to in vitro dietary media. J. Orthod., 36(3):177-85, 2009.

Baccetti, T. \& Franchi, L. Friction produced by types of elastomeric ligatures in treatment mechanics with the preadjusted appliance. Angle Orthod., 76(2):211-6, 2006.

Benson, P. E.; Douglas, C. W. \& Martin, M. V. Fluoridated elastomers: effect on the microbiology of plaque. Am. J. Orthod. Dentofacial Orthop., 126(3):325-30, 2004a.

Benson, P. E.; Shah, A. A. \& Campbell, I. F. Fluoridated elastomers: effect on disclosed plaque. J. Orthod., 31(1):41$6,2004 b$.

Chimenti, C.; Franchi, L.; Di Giuseppe, M. G. \& Lucci, M. Friction of orthodontic elastomeric ligatures with different dimensions. Angle Orthod., 75(3):421-5, 2005.

dos Santos, R. L.; Pithon, M. M.; Martins, F. O.; Romanos, M. T. \& de Oliveira Ruellas, A. C. Evaluation of the cytotoxicity of latex and non-latex orthodontic separating elastics. Orthod. Craniofac. Res., 13(1):28-33, 2010.

Eliades, T.; Eliades, G.; Silikas, N. \& Watts, D. C. In vitro degradation of polyurethane orthodontic elastomeric modules. J. Oral Rehabil., 32(1):72-7, 2005.

Han, J.; Ye, L.; Zhang, A. \& Feng. Z. Synthesis, characterization and electrospinning of biodegradable polyurethanes based on poly(epsilon-caprolactone) and L-lysine diisocynate. Sheng Wu Yi Xue Gong Cheng Xue Za Zhi, 27(6):1274-9, 2011.

Huget, E. F.; Patrick, K. S. \& Nunez, L. J. Observations on the elastic behavior of a synthetic orthodontic elastomer. J. Dent. Res., 69(2):496-501, 1990.

Kim, S. H. \& Lee, Y. K. Measurement of discolouration of orthodontic elastomeric modules with a digital camera. Eur. J. Orthod., 31(5):556-62, 2009.

Kwon, Y. H.; Huo, M. S.; Kim, K. H.; Kim, S. K. \& Kim, Y. J. Effects of hydrogen peroxide on the light reflectance and morphology of bovine enamel. J. Oral Rehabil., 29(5):4737, 2002.

Lacerda Dos Santos, R.; Pithon, M. M. \& Romanos, M. T. The influence of $\mathrm{pH}$ levels on mechanical and biological properties of nonlatex and latex elastics. Angle Orthod., 82(4):709-14, 2012.

Mohamed, M. H.; Wilson, L. D.; Headley, J. V. \& Peru, K. M. Investigation of the sorption properties of b-cyclodextrinbased polyurethanes with phenolic dyes and naphthenates. J. Colloid Interface Sci., 356(1):217-26, 2011.

Nishio, C.; da Motta, A. F.; Elias, C. N. \& Mucha, J. N. In vitro evaluation of frictional forces between archwires and ceramic brackets. Am. J. Orthod. Dentofacial Orthop., 125(1):56-64, 2004

Pithon, M. M.; dos Santos, R. L.; Ruellas, A. C. \& Sant'Anna, E. F. One-component self-etching primer: a seventh generation of orthodontic bonding system? Eur. J. Orthod., 32(5):56770,2010

Renick, M. R.; Brantley, W. A.; Beck, F. M.; Vig, K. W. \& Webb C. S. Studies of orthodontic elastomeric modules. Part 1 : glass transition temperatures for representative pigmented products in the as-received condition and after orthodontic use. Am. J. Orthod. Dentofacial Orthop., 126(3):337-43, 2004.

Ryu, C.; Namura, Y.; Tsuruoka, T.; Hama, T.; Kaji, K. \& Shimizu, $\mathrm{N}$. The use of easily debondable orthodontic adhesives with ceramic brackets. Dent. Mater. J., 30(5):642-7, 2011.

Samruajbenjakul, B. \& Kukiattrakoon, B. Shear bond strength of ceramic brackets with different base designs to feldspathic porcelains. Angle Orthod., 79(3):571-6, 2009.

Santos, R. L.; Pithon, M. M.; Martins, F. O.; Romanos, M. T. \& Ruellas, A. C. Cytotoxicity of latex and non-latex orthodontic elastomeric ligatures on L929 mouse fibroblasts. Braz. Dent. J., 21(3):205-10, 2011.

von Fraunhofer, J. A.; Coffelt, M. T. \& Orbell, G. M. The effects of artificial saliva and topical fluoride treatments on the degradation of the elastic properties of orthodontic chains. Angle Orthod., 62(4):265-74, 1992.

Correspondence to:

Dauro Douglas Oliveira

Av. Dom José Gaspar, 500

Prédio 46, Sala 106

CEP 30535-610

Belo Horizonte MG

BRAZIL

Received: 03-01-2014

Accepted: 23-10-2014

Email: dauro.bhe@gmail.com 